\title{
Calmness Study for Container Handling Ports with Open Basin Systems Using Numerical Modeling
}

\author{
M.A. Khalifa \\ 20 El-Lahoun St. Zezinea, Alexandria, Egypt \\ coastportcop@yahoo.com
}

\begin{abstract}
Container handling ports with open basin system are considered as a modern trend in planning layouts. This option becomes very attractive, in case of the suitability with the existing environmental conditions. In this research, a case study for an open basin port for container handling activity was treated. A preliminary layout was suggested and modified via carrying out the full wave agitation modeling and analyses. The modeling work was carried out by using a calibrated finite element (2-D) module with the advantage of power graphics. Based on the modeling results, the suggested open basin layout was efficiently adjusted via berths allocation, changing their orientation or changing either their type or construction materials.

The research arrived to a group of conclusions that carrying out the calmness studies (full agitation analyses) and comparing the results against the international guidelines (as PIANC) helps to have the most efficient port planning.
\end{abstract}

\section{Introduction}

The open basin system is considered as one of the most important modern trends in port planning state of art, especially the ones working in container handling activity. The traditional/classic planning for ports is the one with closed basin system. The thinking comes to use the open basin system ports, when a certain location has a natural shelter from the environmental conditions (as wind especially cyclones, current, waves, tidal variations, etc.). For the required studies, the environmental data should be available to be analyzed statistically. Based on these statistical studies, the sheltered area/sector from the environmental effects (especially waves attack) should be determined. These ports with open basin have the advantages of economic construction and the ease of 
berths location and orientation changing towards the natural deep water. This option helps to have the natural balance between cut and fill and so have an economic dredging solution. The port calmness studies are considered with a vital importance for preferring a certain proposed planning and so proceeding in its construction than others. The open basin planning always provides the possibility to start with constructing a few numbers of berths from the sheltered direction from waves attack. This makes this option more attractive than the classic closed basin one, which requires constructing breakwaters with a quite high cost with the first development phase of the port project. The mathematical modeling is considered very important for selecting the preferred option(s) from the proposed planning alternatives to ensure an efficient handling attitude based on the international regulations for calmness as the well known ones of PIANC (The International Navigation Association) (PIANC, 1997; BS-6349, 2000; and IAPH, 2009).

This research discusses a case study for open basin port planning of layout for a hop (mega scale) port, working in container handling activities. Besides, it also highlights on the sensitivity analysis study as an explanatory example for the effects of different carried out modifications on the port layout to provide more calmness (UNCTAD, 1985; DMC, 1999; and IAPH, 2009).

\section{Port Calmness due to Wave Agitation Studies}

\section{Calmness Criteria to be Fit for Port Layouts}

The acceptable calmness criteria for ports differ based on the accommodated vessels types and sizes. Based on recommendations, the general out frame is the complete stability and safety for vessels in approach, berthing/deberthing and cargo handling stages. For the approach stage, the tug assistance can be considered efficient with a maximum wave height of $1.50 \mathrm{~m}$ for the outer approach (out of breakwater shelter in the open sea). For the sheltered part of the approach channel (by breakwaters), maximum acceptable wave height is in order of $0.90 \mathrm{~m}$. For the container handling port basin and berthing areas, maximum acceptable one is in order of $0.50 \mathrm{~m}$, based on PIANC recommendations. For the modern generations of container vessels, the cellular guides to keep containers in place with using the GPS positioning system are normally used. With the existence of such guides, the 
possibility of the containers to be stuck is existed in case of sharp movement's occurrence. Thus, maximum acceptable wave height inside the port basin should be less than $0.50 \mathrm{~m}$, to be in order of $0.30 \mathrm{~m}$ if possible. For the other types of vessels, which handle the different commodities rather than containers, the complete calmness is important as well, but with less sensitivity. For the last case, higher wave heights and so a bit less vessels stability during the handling operations can also be acceptable (Groenveld, et al., 1983; Ligteringen, 2000; and Bijker \& Overeem, 2000).

\section{Materials and Methods}

For carrying out the wave agitation studies for the studied port basin, a 2-D numerical finite element module was used. This module has the advantage of power graphics presentation, to represent the happened variation in the significant wave heights in both port basin and approach area close to the port opening. This module can simply solve the wave agitation problems with full components (including the effects of refraction, diffraction, reflection and penetration). In the initial step, the key points (via accurate coordinates) and so the main boundary lines (via connecting the key points) for the inner basin and closed approach should be determined. Thus, the approximate shape for the inner studied area can be determined. After, the studied domain should be transferred into elements with suitable sizes via applying meshing procedures. The quadruplets elements are preferred to be used more than the triangular ones through meshing of the studied domain. For corners and limited (small) areas, the triangular elements with reasonable sizes and angles are preferred in usage. This leads to get reasonable and correct results during the carried out simulation after. For the elements sizes, the best selection is what is called element smart size. This kind of elements has reasonable sizes for efficient representation of the domain. This comes as the meshing procedure as it starts from the outer boundaries of the domain and comes to the inner areas after.

In the next step, the elements of the meshed area (study domain including the port basin and its closed approach stretch) should have the sea salt water specifications. This comes via giving the suitable density value for its elements $\left(1.025 \mathrm{t} / \mathrm{m}^{3}\right.$ for sea salt water). For the studied domain outer boundaries (boundary conditions), suitable values for the reflection coefficient $\left(\mathrm{K}_{\mathrm{r}}\right)$ should be given based on the type of used 
materials in these boundaries. This definition for the boundaries materials comes via the given values of the absorption coefficient $\left(\mathrm{M}_{\mathrm{u}}\right)$. The value of the absorption coefficient $\left(\mathrm{M}_{\mathrm{u}}\right)$ can be directly calculated if the reflection coefficient $\left(\mathrm{K}_{\mathrm{r}}\right)$ value is known. The meaning of absorption/reflection is that the ability of the material to absorb/reflect the wave energy. This comes as given in equation (1) (Blaauw et al., 1981; UNCTAD, 1985; Ligteringen, 2000; and IAPH, 2009).

$$
\mathrm{M}_{\mathrm{u}}=1-\left(\mathrm{K}_{\mathrm{r}}\right)^{2}
$$

Where:

$\mathrm{M}_{\mathrm{u}}=$ the absorption coefficient for the breakwater/outer protection material.

$\mathrm{K}_{\mathrm{r}}=$ the reflection coefficient for the breakwater/outer protection material.

For the guiding values of the absorption coefficient $\left(\mathrm{M}_{\mathrm{u}}\right)$, they are variable from full absorption $(100 \%$ absorption $=0 \%$ reflection, as the case of the inner absorbing beaches) and ( $0 \%$ absorption $=100 \%$ reflection, as a theoretical value).

The used finite element module can be used to solve the acoustic and fluid structure interaction problems. The primary elements used for performing acoustic analysis based upon a pressure formulation in which the element shape functions refer to the pressure variation associated with an acoustic wave. For the fluid-structure interaction, it is not only the acoustic response affected by the presence of the structure, but also the structural dynamic response is significantly affected by the presence of the fluid. The primary assumption made in acoustic and fluid-structure interaction analysis is that the fluid behaves as an ideal acoustic medium. The mathematical description of how an acoustic fluid behaves is based on expressions that represent continuity (conservation of mass), fluid elastic properties (constitutive equation) and force equilibrium. The details of these equations are as explained after. The structural response is dependent upon the pressure loads applied by the fluid and the fluid pressures are themselves affected by the structural motion. The basic characteristics of the three frequency domain associated with fluid structure interaction problems are as presented in the law, high and intermediate frequency responses. For low frequency response, it is characterized by a condition in which the short wave length structural 
motions do not effect long wave length (low frequency) acoustic waves. No significant long wavelength acoustic energy is radiated away from the structure and the fluid simply moves around the structure. For the high frequency response, it is characterized by a condition in which the structural motions efficiently exit short wave length (high frequency) acoustic waves that radiate energy from the structure. If the structural motions are visualized to be uniform over a region that is large as compared to the acoustic wave length, then the localized fluid response is nearly identical to that produced by the plane wave solution to the acoustic wave Equation. For the intermediate frequencies, the structural response at intermediate frequencies in which the acoustic wave lengths are of the same order of magnitude as the structural vibration wave lengths is relatively complex with near field acoustic resonance interacting with the structure. For the pressure formulated elements, the formulation of the pressure based fluid elements expressed the unknown acoustic pressure within an element in terms of the pressure values at the nodes (Valihrach, 2006; Biosolid, 2009; and Scribd, 2009).

\section{Conservation of Mass Equation}

We consider the changes for a fluid that is moving through our domain. There is no accumulation or depletion of mass, so mass is conserved within the domain. Since the fluid is moving, defining the amount of mass gets a little tricky. Let's consider an amount of fluid that passes through point "a" of our domain in some amount of time (t). If the fluid passes through an area (A) at velocity (V), we can define the volume (Vol) to be as given in equation (2) (NASA, 2009):

$$
\operatorname{Vol}=(A * V * t)
$$

A units check gives area $*$ length/time $*$ time $=$ area $*$ length $=$ volume. Thus the mass at point "a" $\left(\mathbf{m}_{\mathbf{a}}\right)$ is simply density $(\mathbf{r})$ times the volume at "a" as given in equation (3) (NASA, 2009).

$$
m_{a}=(r * A * V * t) * a
$$

If we compare the flow through another point in the domain, point "b," for the same amount of time $\mathbf{t}$, we find the mass at "b" $\left(\mathbf{m}_{\mathbf{b}}\right)$ to be the density times the velocity times the area times the time at " $b$ " as given in equation (4) (NASA, 2009): 


$$
m_{b}=(r * A * V * t) * b
$$

From the conservation of mass, these two masses are the same and since the times are the same, we can eliminate the time dependence as given in equation (5) (NASA, 2009).

$$
(r * A * V)=\text { constant }
$$

\section{Constitutive Equation}

The mechanical analog for a Newtonian fluid is a dashpot. The simple constitutive relationship for a dashpot indicates that the force in the fluid depends on the rate the dashpot is displaced, or equivalently the velocity of the dashpot.

The constitutive equation for a fluid may be written as given in equation (6) (ATM, 2009):

$$
F^{d}=\mu \frac{d u^{d}}{d t}=\mu \dot{u}^{d}
$$

Where:

$F_{d}=$ The force in the fluid, $u=$ velocity of the fluid, $t=$ time of displacement $\& \mu=$ viscosity of the fluid.

The dot over the $\mathrm{u}$ in the equation indicates differentiation with respect to time (ATM, 2009).

\section{Wave Agitation Modeling Study for a Protected Open Basin Port}

The used finite element module calibration was carried out for a case with similar conditions to the studied case. The calibration procedure comes with a relative difference in order of (10-15\%). This comes via comparison between both the available measured and model calculated values. Wave agitation calculations have been performed by using the above described finite element module. Full wave agitation analysis is considered (refraction, diffraction, reflection/absorption and penetration). The wave direction has been taken into consideration as being for each case separately based on its environmental conditions. The main deficiency in the used module is that it does not consider the effect of the 
wave directional spreading (unidirectional wave propagation simulation only). Table 1 presents the guided reflection and absorption coefficients $(\mathrm{Kr}) \&(\mathrm{Mu})$ values to be used for the wave agitation study (UNCTAD, 1985; BS-6349, 2000; and U.S. Army Corps of Engineers, 2002).

Table 1. Guided reflection and absorption coefficients $\left(K_{r}\right) \&\left(M_{u}\right)$ values to be used for the wave agitation study.

\begin{tabular}{|l|c|c|l|}
\hline \multicolumn{1}{|c|}{ Boundary } & \multicolumn{1}{|c|}{$\begin{array}{c}\text { Reflection } \\
\text { coefficients } \\
\left(\mathbf{K}_{\mathbf{r}}\right)\end{array}$} & $\begin{array}{c}\text { Absorption } \\
\text { coefficients } \\
\left(\mathbf{M}_{\mathbf{u}}\right)\end{array}$ & \multicolumn{1}{|c|}{ Remarks } \\
\hline Along the quay walls & 0.80 & 0.36 & Partial reflection \\
\hline The breakwaters, piers & 0.70 & 0.51 & Partial reflection \\
\hline The beach & 0.00 & 1.00 & Full absorption \\
\hline
\end{tabular}

The refraction effect is included in the analysis according to the variation in the wave propagation speed $(\mathrm{C}=\mathrm{L} / \mathrm{T})$. It varies according to the wave length variation $(\mathrm{L})$ related to the depth differences among the access channel, turning area and the inner basin of the port. Another main important governing factor is the wave period $(\mathrm{T})$. For the meshed domain, the element size varies between $(1 / 8$ to $1 / 10)$ from the near shore wave length close to the port entrance area. Full harmonic/dynamic load impact analysis is considered in the solution. In the model runs, the unit significant wave height (significant wave height, $\mathrm{H}_{\mathrm{s}}=1.00 \mathrm{~m}$ ) is used near the port entrance based on the fact of existing a linear relation between the wave height(s) inside and outside the port (Goda, 1985; PIANC, 1997; U.S. Army Corps of Engineers, 2002; and IAPH, 2009).

Figures $1 \& 2$ present the proposed different development phases for this port before and after carrying out the required modifications, respectively. The development phases describe the development in berths construction with time progress. Every phase comes after five years from the previous one $\left(1^{\text {st. }}\right.$ in year $2005,2^{\text {nd. }}$ in year $2010,3^{\text {rd. }}-$ in year 2015 and $4^{\text {th. }}$ - in year 2020). The increased number of berths is not constant. It varies with the expected development in the handled containers capacity via the ort (in TEUs, Twenty Feet Equivalent Units). As given in Fig. 1 $\& 2$, the berths for different development phases were indicated with different colors for the ease of observation in the development future plans. These carried out modifications come through a group of runs by the modeling works. 
Figure 3 presents an example from this stepped modeling work for wave attack from south (S) and south west (SW), respectively. The development steps are carried out by both the allocation for the place of some berths and changing in their type(s) and simulated/modeled material with specific reflection coefficients. Other modifications come with changing the berths orientation, see Fig. $1 \& 2$ for layout before and after modification. The need for such modifications is discussed in details through the procedure of the carried out sensitivity analyses. From the modeling wave results, as will be presented after, it is clear that the disturbance inside the open port basin after modification is mainly due to wave diffraction and not their direct penetration.

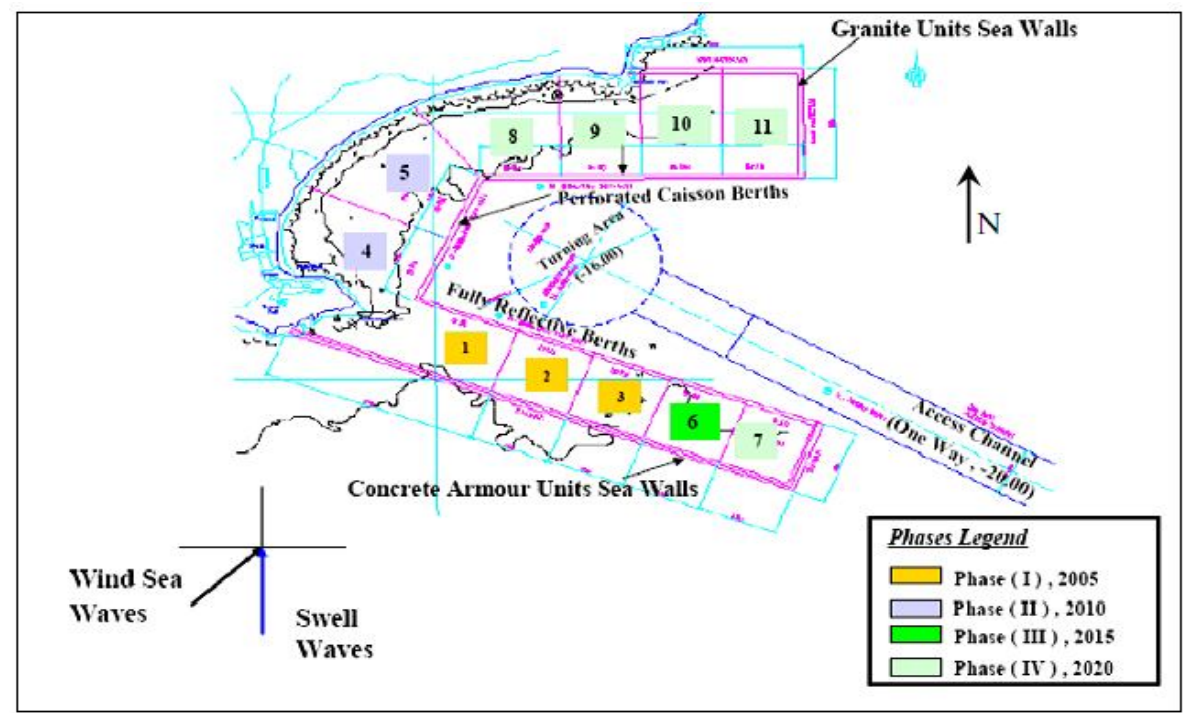

Fig. 1. Different development phases for an open basin port project before carrying out any of the required planning modifications.

\section{Sensitivity Analyses for Wave Calmness in the Port Basin}

One of the most important tasks to be carried out is the sensitivity analyses for wave heights inside the port (entrance, turning basin area and berths). These analyses are carried out as a comparative study between the cases before and after carrying out any required modification(s). Based on such modifications, the location of some berths, berths orientation, the type of used berths and the used material for berths (construction materials and/or characteristics) are modified. Such comparative studies give good and realistic engineering overview 
about the expected effect(s) of any changes in the port planning and design and so helps the decision maker(s) as a supporting tool. Thus, the decision of taking an option into consideration and leaving another can be made (Van, 1993; Ligteringen, 2000; and U.S. Army Corps of Engineers, 2002).



Fig. 2. Different development phases for the open basin port after carrying out the required planning modifications.

After, the cost/benefit analysis comes, which is out of the scope of that research. In the following discussion, some stages which represent the required modifications are discussed. Based on these sensitivity analyses, the final decisions were taken for the real required modifications to be made.

\section{Example for the Carried Out Sensitivity Analysis for Phase Number (III)}

This case presents a comparison between the wave heights variation inside the port basin in the development phase number (III) considering either fully reflective caissons (Case 1) or absorbing perforated caisson (Case 2) for the berths after constructing the berths of the development phase number (I). In phase number (I), all the berths are caissons with fully reflective effect. Figures 3.1 and 3.2 present the wave agitation modeling for the mega scale open basin port, after carrying out all the required modifications. Figure 4 presents the selected check points for 
the calmness checking, before modification for the studied open basin port system, different proposed development phases. Figure 5 presents the selected check points for the calmness checking, after modification for the studied open basin port system, for the different proposed development phases. The main target of this comparison is to highlight on the importance of using the perforated caisson berths for the quay walls after the development phase number (I) in the modified layout, starting from the second development phase. It is important to mention that the extended berth for phase number (III) will be constructed from the fully reflection type. A general reduction for the wave heights inside the port area gives an advantage to the perforated caissons option over the fully reflective ones as continues effect on phase number (III). This will lead to fix the modified actions of the modified layout in both phases number (II) \& (III) for the berths type. Point number (6) in the berthing area will meet the highest reduction percentage. In the turning are, point number (13) meets the highest reduction percentage. Figure 6 presents the wave heights variation for the selected checking points inside the port area for the development phase number (III), considering either the fully reflective or perforated caissons berths after phase number (I). Table 2 presents the reduction percentages in the wave heights in the different checking points, as a percentage for (Case 2) over (Case 1) as described above.

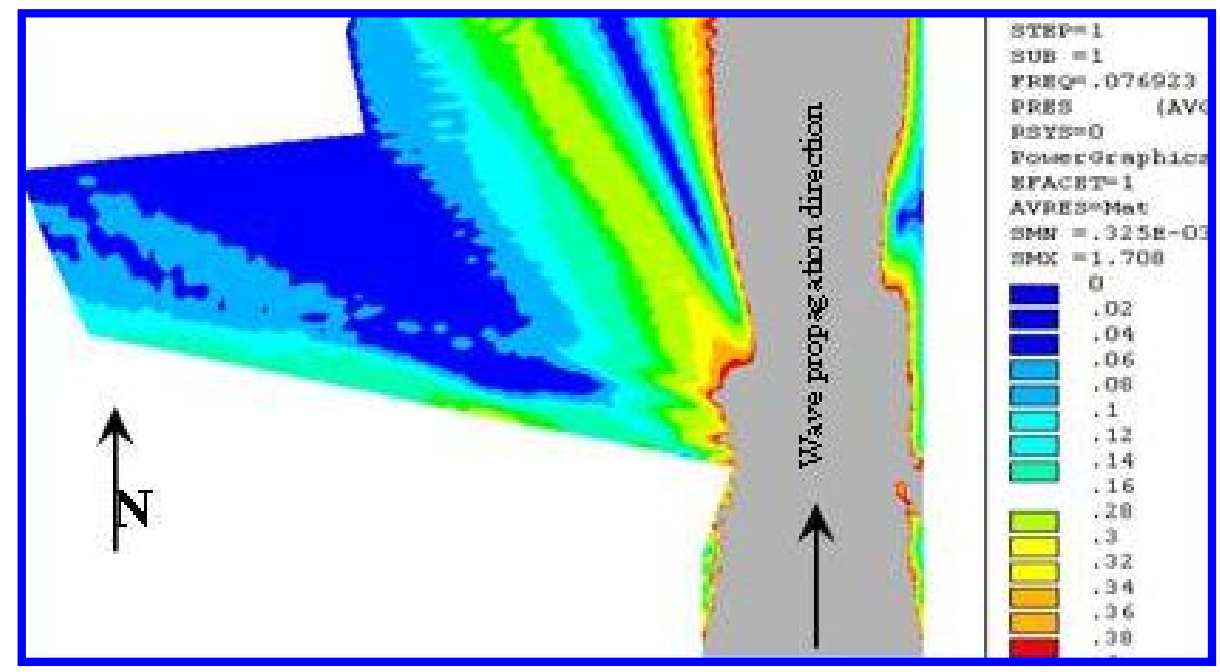

Fig. 3.1. Waves attack: propagation direction coming from south. 


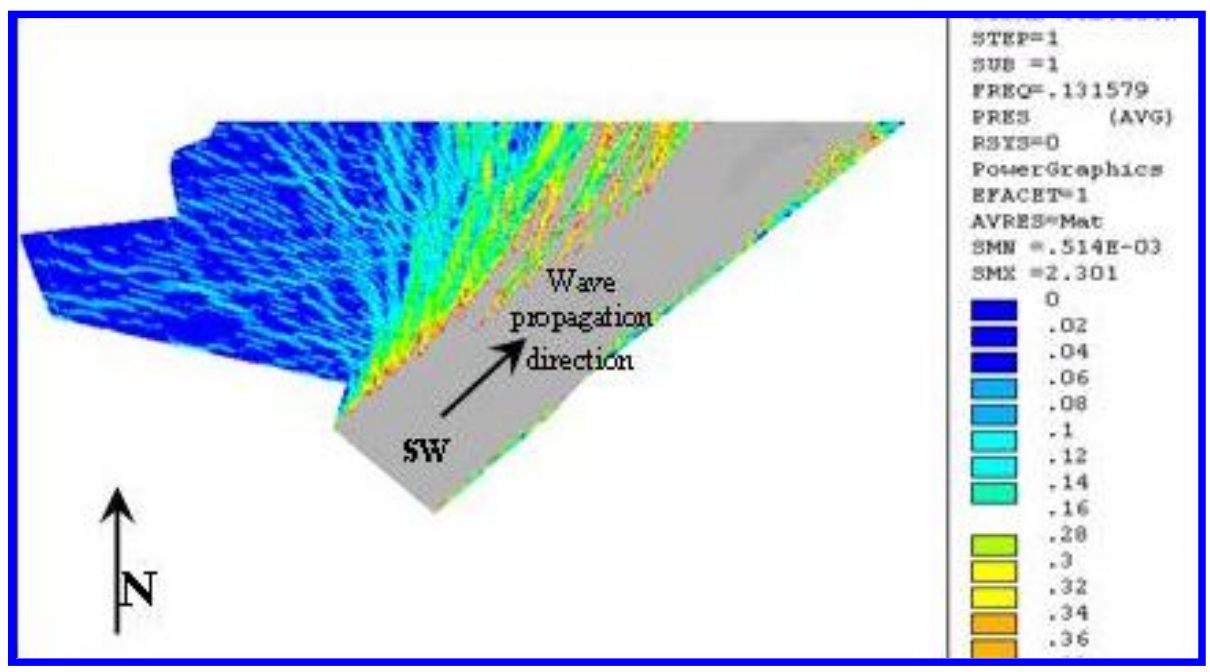

Fig. 3.2. Waves attack: propagation direction coming from South West (SW).

Figures $3.1 \& 3.2$. Wave agitation modeling for the mega scale open basin port, after carrying out all the required modifications.

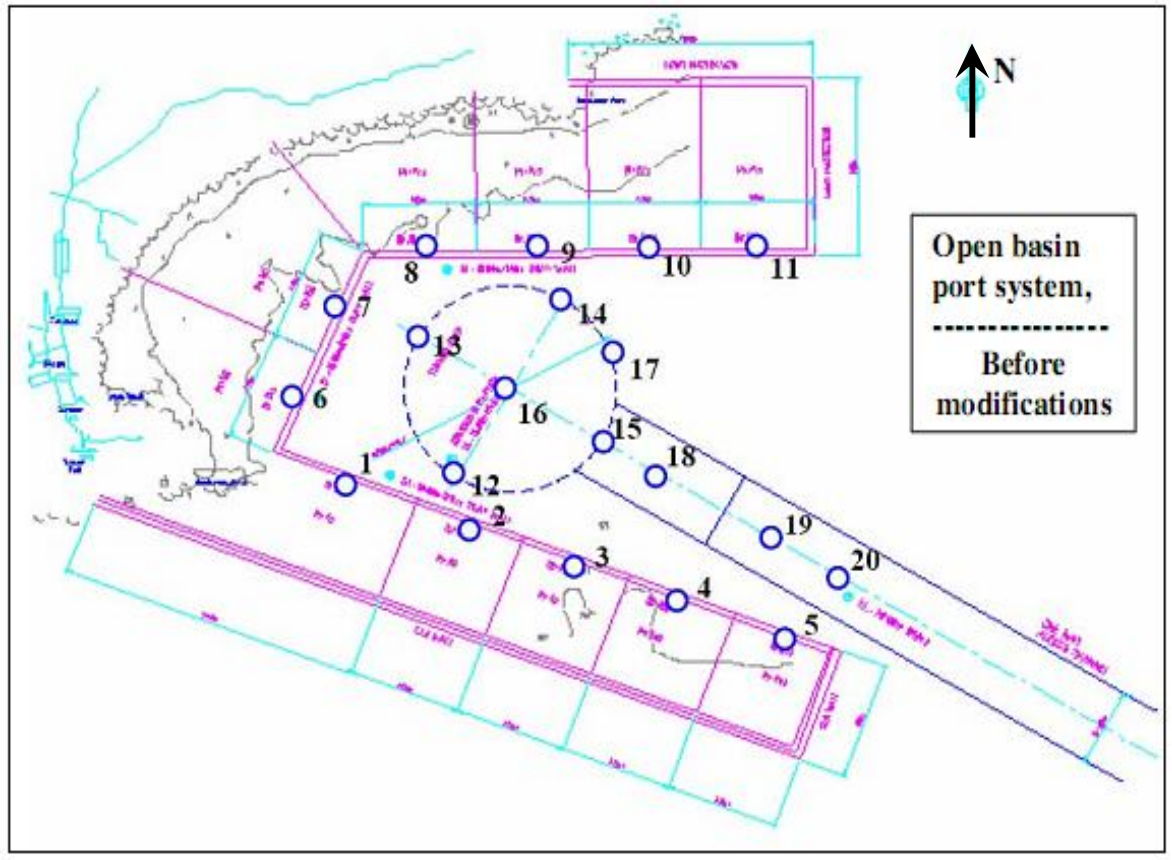

Fig. 4. Selected check points for the calmness checking, before modification, for the studied open basin port system, different proposed development phases. 


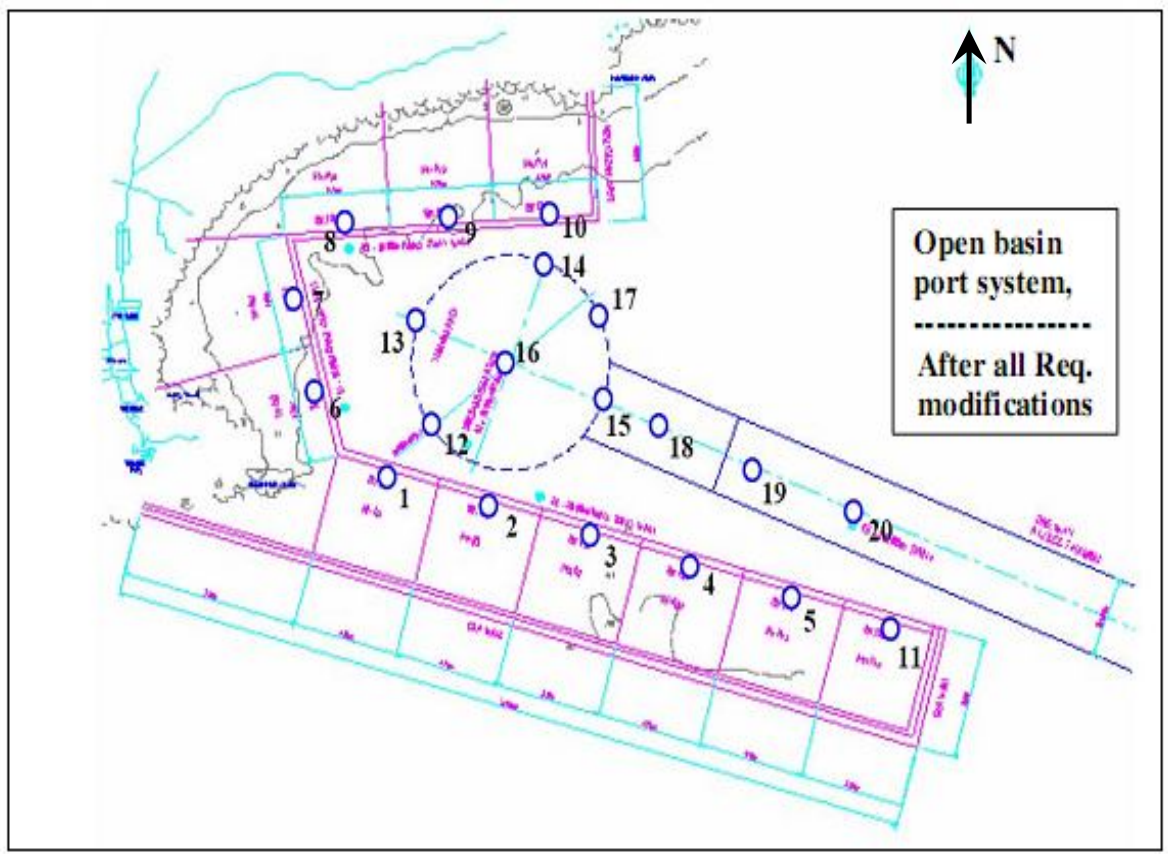

Fig. 5. Selected check points for the calmness checking, after modification for the studied open basin port system, for the different proposed development phases.

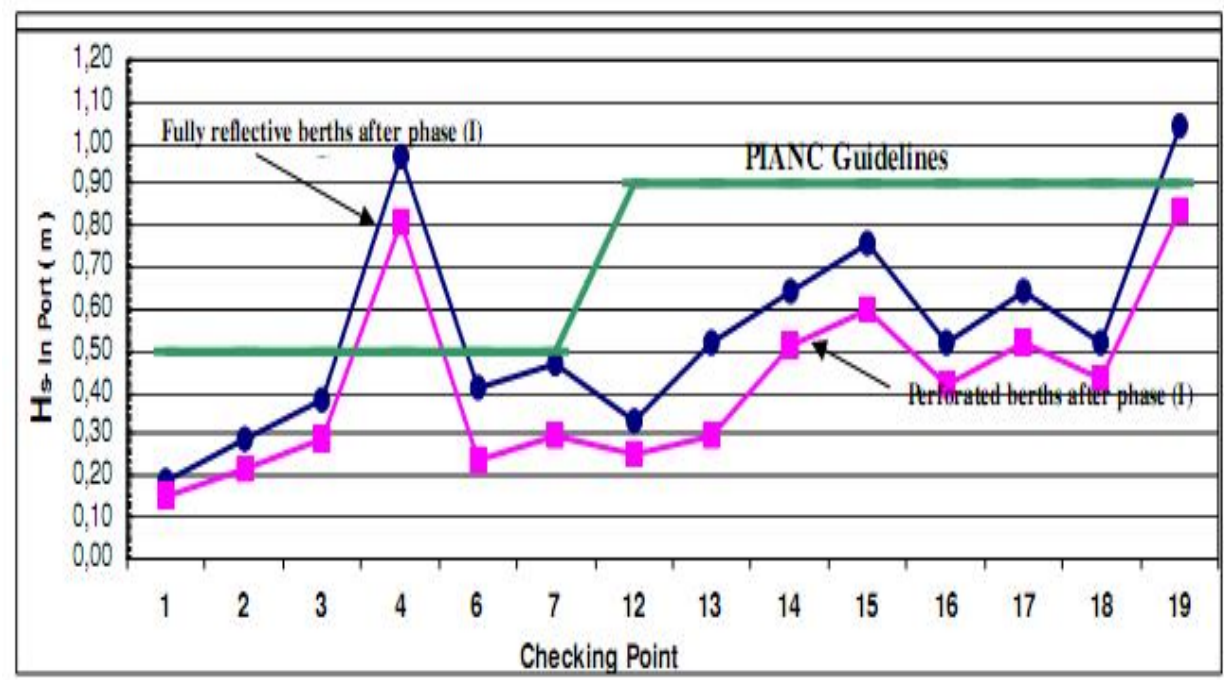

Fig. 6. Wave heights variation for the selected checking points inside the port area for phase (III), considering either the fully reflective or perforated caisson berths, after phase (I). 
Table 2. Wave height reduction for the checking points for phase (III) after carrying out all the required modifications.

\begin{tabular}{|c|c|c|c|c|c|}
\hline $\begin{array}{c}\text { Check } \\
\text { point }\end{array}$ & $\begin{array}{c}\text { Wave height } \\
\text { reduction (\%) }\end{array}$ & $\begin{array}{c}\text { Check } \\
\text { point }\end{array}$ & $\begin{array}{c}\text { Wave height } \\
\text { reduction (\%) }\end{array}$ & $\begin{array}{c}\text { Check } \\
\text { point }\end{array}$ & $\begin{array}{c}\text { Wave height } \\
\text { reduction (\%) }\end{array}$ \\
\hline \hline $\mathbf{1}$ & $-21 \%$ (U.L.) & $\mathbf{7}$ & $-36 \%$ (U.L.) & 16 & $-19 \%$ (U.L.) \\
\hline \hline $\mathbf{2}$ & $-24 \%$ (U.L.) & $\mathbf{1 2}$ & $-23 \%$ (U.L.) & 17 & $-19 \%$ (U.L.) \\
\hline \hline $\mathbf{3}$ & $-24 \%$ (O.L.) & $\mathbf{1 3}$ & $-42 \%$ (U.L.) & 18 & $-16 \%$ (U.L.) \\
\hline \hline $\mathbf{4}$ & $-16 \%$ (U.L.) & $\mathbf{1 4}$ & $-20 \%$ (U.L.) & $\mathbf{1 9}$ & $-19 \%$ (U.L.) \\
\hline \hline $\mathbf{6}$ & $-41 \%$ (U.L.) & $\mathbf{1 5}$ & $-21 \%$ (U.L.) & & \\
\hline
\end{tabular}

- The wave height reduction evaluated as a percentage between case (2) over case (1).

- Negative sign means wave height reduction inside the port and so more calmness

- $($ O.L. $)=$ Over limits of PIANC. \& (U.L.) = Under limits of PIANC.

Sensitivity Analyses for the Caisson Berths Location and Orientation Changing

This case presents a comparison between the wave heights variations inside the port area for the modified layout before (Case A) and after (Case B) the berths orientation and locations modifications for this modified layout. Fully reflective caisson quay walls after phase number (I) are considered. This comparison is considered between the original layout before carrying out any modifications and after all the required modifications. As recognized, a sharp reduction for the wave height values happens with modifying the location and orientation of the caisson quay wall. The percentages of wave height reduction clearly vary from a point to another, according to its proximity to the wave high reflection among berths. The highest reduction occurs close to the checking point number (10) for the berthing area. Checking point number (15) is the one, which will meet the maximum reduction on the turning basin area. It is clear that the caisson type and orientation changing for the berths cause a big difference in the wave heights distribution inside the port area and so improve the situations for the container handling operations. This leads to fix the decided modifications for the layout. Table 3 presents the reduction percentages for the wave heights as a percentage of (Case A) over (Case B), as descried above. Figure 7 presents the wave heights variation for the selected checking points inside the port area, phase number (IV) before and after changing the berths orientation considering fully reflective caissons after phase (I). 
Table 3. Wave height reduction percentages for the checking points, in development phase number (IV).

\begin{tabular}{|c|c|c|c|c|c|}
\hline $\begin{array}{c}\text { Check } \\
\text { point }\end{array}$ & $\begin{array}{c}\text { Wave height } \\
\text { reduction (\%) }\end{array}$ & $\begin{array}{c}\text { Check } \\
\text { point }\end{array}$ & $\begin{array}{c}\text { Wave height } \\
\text { reduction (\%) }\end{array}$ & $\begin{array}{c}\text { Check } \\
\text { point }\end{array}$ & $\begin{array}{c}\text { Wave height } \\
\text { reduction (\%) }\end{array}$ \\
\hline 1 & $-36 \%$ (O.L.) & 8 & $-38 \%$ (O.L.) & 15 & $-83 \%$ (U.L.) \\
\hline 2 & $-37 \%$ (O.L.) & 9 & $-39 \%$ (O.L.) & 16 & $-39 \%$ (U.L.) \\
\hline 3 & $-10 \%$ (O.L.) & 10 & $-68 \%$ (O.L.) & 17 & $-62 \%$ (U.L.) \\
\hline 4 & $-11 \%$ (O.L.) & 11 & $-66 \%$ (O.L.) & 18 & $-67 \%$ (U.L.) \\
\hline 5 & $-57 \%$ (O.L.) & 12 & $-28 \%$ (U.L.) & 19 & $-51 \%$ (U.L.) \\
\hline 6 & $-33 \%$ (O.L.) & 13 & $-54 \%$ (U.L.) & 20 & $-57 \%$ (U.L.) \\
\hline 7 & $-56 \%$ (O.L.) & 14 & $-58 \%$ (U.L.) & & \\
\hline
\end{tabular}

- The wave height reduction evaluated as a percentage between case (2) over case (1) .

- Negative sign means wave reduction inside the port and so more calmness.

- $($ O.L. $)=$ Over limits of PIANC. \& (U.L. $)=$ Under limits of PIANC.

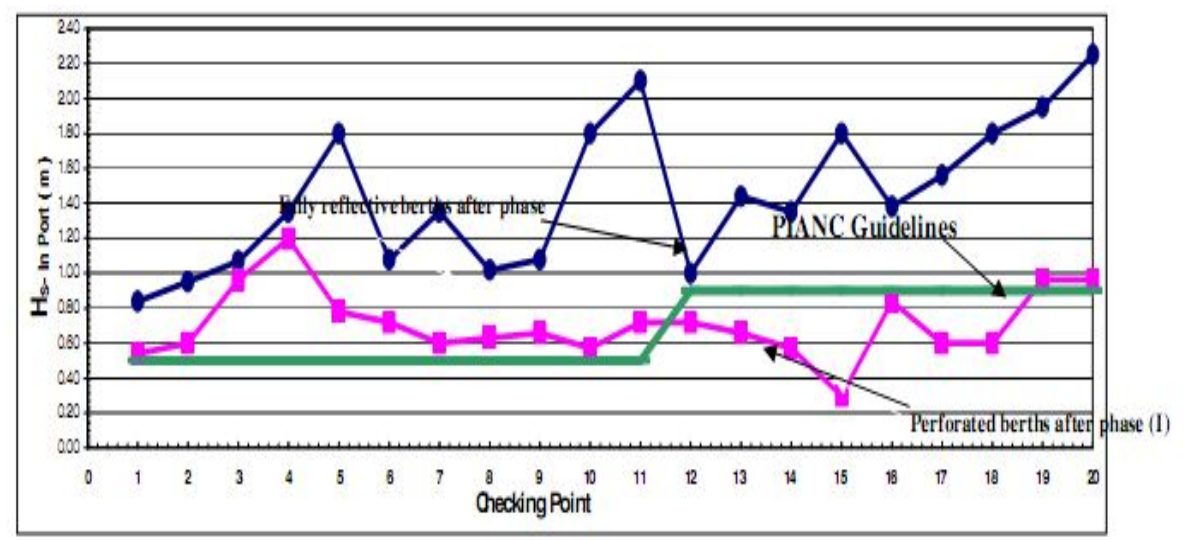

Fig. 7. Wave heights variation for the selected checking points inside the port area, phase number (IV) before and after changing the berths orientation considering fully reflective caissons after phase (I).

Sensitivity Analyses for Cases Before and After the Berths Orientation and Type Modification

This case presents a comparison between the wave heights variations inside the port area for before (Case A) and after (Case B) the berths orientation changing and type modification. Fully reflective and perforated caisson quay walls are considered for all berths after the development phase number one for the mentioned cases, respectively. Table 4 presents the reduction percentages in the wave heights as a percentage for (Case B) over (Case A) as described above. Figure 8 presents wave heights variation for the selected checking points inside 
the port area, Phase (IV) considering either fully reflective or perforated caissons after the development phase number (I). It is clear that the situation was improved in the majority of points with quay walls type modification, but not much as the high effect of reflection among berths still existing. Point number (15) on the turning area has the most improvement. For the berthing area, the calmness at point number (8) meets the highest reduction percentage. Generally, the wave heights within the port area reduced and become suitable to give the required calmness environment for the container handling activities.

Table 4. Wave heights reduction percentages for the check points, in development phase number (IV).

\begin{tabular}{|c|c|c|c|c|c|}
\hline $\begin{array}{c}\text { Check } \\
\text { point }\end{array}$ & $\begin{array}{c}\text { Wave height } \\
\text { reduction (\%) }\end{array}$ & $\begin{array}{c}\text { Check } \\
\text { point }\end{array}$ & $\begin{array}{c}\text { Wave height } \\
\text { reduction (\%) }\end{array}$ & $\begin{array}{c}\text { Check } \\
\text { Point }\end{array}$ & $\begin{array}{c}\text { Wave height } \\
\text { reduction (\%) }\end{array}$ \\
\hline 1 & $-33 \%$ (O.L.) & 8 & $-86 \%$ (O.L.) & 15 & $-40 \%$ (U.L.) \\
\hline 2 & $-30 \%$ (O.L.) & 9 & $-77 \%$ (O.L.) & 16 & $-84 \%$ (U.L.) \\
\hline 3 & $-50 \%$ (O.L.) & 10 & $-63 \%$ (O.L.) & 17 & $-73 \%$ (U.L.) \\
\hline 4 & $-50 \%$ (O.L.) & 11 & $-33 \%$ (U.L.) & 18 & $-68 \%$ (U.L.) \\
\hline 5 & $-38 \%$ (O.L.) & 12 & $-58 \%$ (U.L.) & 19 & $-63 \%$ (U.L.) \\
\hline 6 & $-58 \%$ (O.L.) & 13 & $-77 \%$ (U.L.) & 20 & $-50 \%$ (U.L.) \\
\hline 7 & $-70 \%$ (O.L.) & 14 & $-68 \%$ (U.L.) & & \\
\hline
\end{tabular}

- The wave height reduction evaluated as a percentage between case (2) over case (1).

- Negative sign means wave reduction inside the port and so more calmness.

- $($ O.L. $)=$ Over limits of PIANC. \& (U.L.) = Under limits of PIANC.

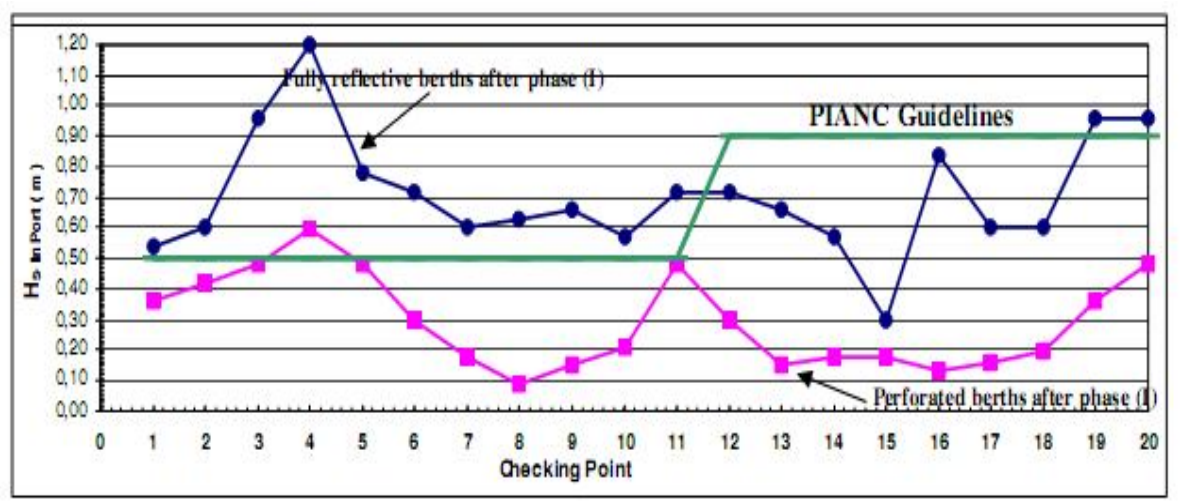

Fig. 8. Wave heights variation for the selected checking points inside the port area, phase number (IV) considering either fully reflective or perforated Caissons after the development phase number (I). 


\section{Conclusions}

The study gave conclusions for calmness studies for port planning and design through presenting a case study. This case study is for a hop port with an open basin system. The conclusions are as follows:

- Generally, the results of the numerical modeling wave agitation calmness studies on ports with open basin system lead to liable and accurate solutions. They give a good guidance for the required modifications required in the final layouts based on the calmness criteria, following the international regulations as PIANC. These regulations give good direction to have an acceptable value for the wave height of $0.5 \mathrm{~m}$ and $0.9 \mathrm{~m}$ for the studied domain including both port basin and approach areas, respectively.

- The proposed layouts modifications as changing berths location and orientation, the orientation of the entrance opening and the access channel and the type and materials berthing facilities help effectively in providing the required calmness for the port layouts. Thus, the efficient handling for containers can be achieved.

The calmness study shows some required modifications in the berths locations, orientation and type. These suggested modifications are summarized as follows:

- Changing the orientation for berths in the development phase number (II).

- Perforated caisson quay walls to be used in the development phase number (II).

- Transferring the last berth for phase number (IV) from the northern boundary to the southern one.

- Perforated caisson quay walls to be used for the northern berths of the development phase number (IV).

The port layout before and after applying all the required modifications are as presented in details in this study. Based on the obtained results, the following conclusions are observed.

- Along the proposed berths (different phases), the wave heights are dramatically reduced compared to the incident wave height values.

- Towards the surrounding beach direction in the development phases number (I), (II) and (III), a big damping of the wave height values occur due to the existence of both beach and perforated caissons. This 
comes via absorbing the wave energy, which cause calmness disturbance in the port basin area.

- The results give a pointer that the extension of the port for the last development phase option after constructing berth number (10) should be made in the southern boundary of the port. The reason is to benefit from the natural deep water existence in that boundary area.

- Berth number (1) in the development phase number (I), just beside the headland area, faces the lowest wave height values and has the most calm conditions for the container handling activities.

- Berth number (11) to be constructed in the development phase number (IV). The outer tip of the port in the southern proposed development boundary faces the highest wave height and so has the least calmness within all berths for the different proposed development phases.

- The wave height inside the turning area is rarely exceeded by $0.9 \mathrm{~m}$ for different wave conditions, after carrying out all the required modifications. This makes a good environment for the tug assistance to have a full efficiency in the port area and the sheltered part of the access channel (within the seawall shelter).

\section{Acknowledgements}

Thanks to ALLAH, who gives the power and provides the knowledge. Many deep thanks to the kind reviewers who give the compulsory and valuable directions, without which, this manuscript can not be suitably adjusted for publishing in this professional scientific journal.

\section{References}

ATM (2009) http://www.appliedtm.com/index.htm, (accessed: March 2009).

Bijker, E.W. and Overeem, V.J. (2000) Access Channel, Technical Notes, The Netherlands.

Biosolid (2009) Mechanics - modeling and applications, http://www.engin.umich.edu/ class/bme456/-ch7consteqviscoelasticity/bme456consteqviscoelasticity.htm, (accessed: March 2009).

Blaauw, H.G. Koeman, J.W. and Strating, J. (1981) Nautical contribution to an integrated port design, Delft Hydraulics, The Netherlands.

BS-6349 (2000) Code of Practice for Maritime Structures "Part 1" - General Criteria, British Standards Institution, UK.

DMC, B.V. (1999) Conceptual Planning of a New Container Port, HPG seminar, The Netherlands.

Goda, Y. (1985) Random Seas and Design of Maritime Structures, ISBN 4-13-068110-9, University of Tokyo Press.

Groenveld, R., Vis, F.C., Deelen, C. and Van Den Berg, J. (1983) Optimization of breakwater lengths in relation to wave penetration, Delft Hydraulics, The Netherlands. 
IAPH (2009) http://www.iaphworldports.org,(accessed, (accessed: March 2009).

Ligteringen, H. (2000) Ports and terminals, TU Delft Univ., The Netherlands.

NASA (2009) Conservation of mass, http://www.grc.nasa.gov/www/K12/ airplane/ mass.html, (accessed: March.2009).

PIANC (1997) Approach Channel a Guide for Design, Report of working group II-30, Brussels, Belgium.

Scribd Org. (2009) http://www.scribd.com/doc/6854967/Finite, Element - Method - Fluid Dynamics, (accessed: March 2009).

U.S. Army Corps of Engineers (2002) "Coastal Engineering Manual - Part III: Coastal Sediment Processes". CERC (Coastal Engineering Research Center, www.ce.ufl.edu/ sheppard/eoc6430/Coastal_Engineering_Manual.htm-(accessed: Oct., 2007).

UNCTAD (1985) Port development, a handbook for planners in developing countries, New York, USA.

Valihrach, J.I. (2006) Integrated Design of Structures and Systems for Construction, Technical University of Ostrava, Center for Integrated Design of Advanced Structures - Czech, Republic. www.cideas.cz/free/okno/technicke_listy/3tlven/TL06EN_1123-4.pdf, (accessed: Oct. - 2007).

Van den Doel, M. (1993) Port Planning and Design. Technical Notes, The Netherlands. 


\title{
در اسة الهدو ء لمو انئ تداول الحاويات ذات الحوض المفتوح باستخدام النمذجة العددية
}

\author{
محمد عوض خليفة \\ r r ش اللاهون، زيزينيا، الإسكندرية- مصر \\ بريد إلكتروني: coastportcop@yahoo.com
}


الاتجاهات الحديثة في مجال التخطيط للمو انئ، وخاصة العاملة في

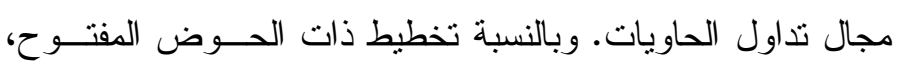
فيبدأ التفكير في استخدامها في الحالات التي يكون فيها موقع الميناء

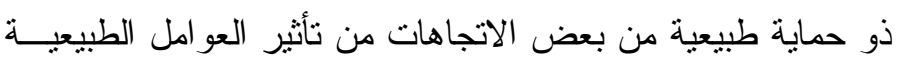

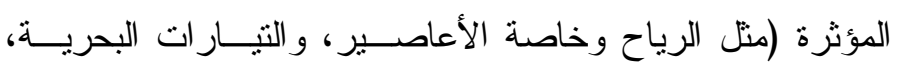

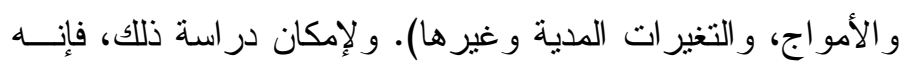

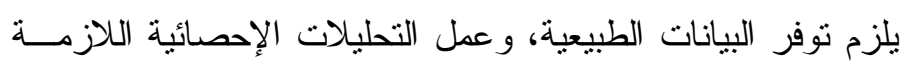

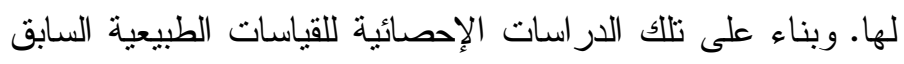
ذكر ها، فإنه يتم تحديد الاتجاهات - القطاعات الاتجاهية المحميـــة



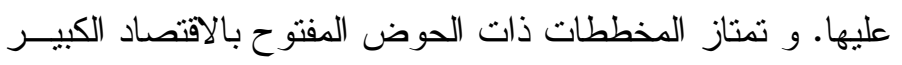



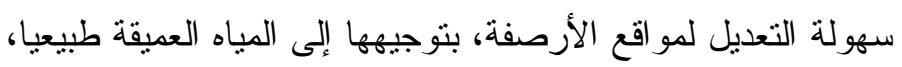

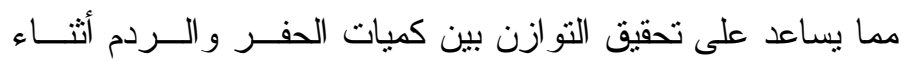
أعمال التنفيذ.

وفي هذه الدراسة، تم عمل دراسات الهدو ء لنموذج ميناء ذي

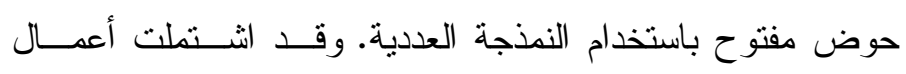


النمذجة على التأثير ات الكاملة للأمو اج المهاجمة للمينـاء (ثــاملة





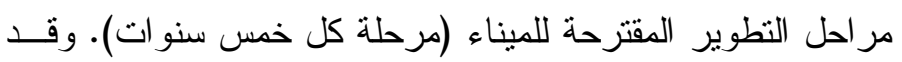

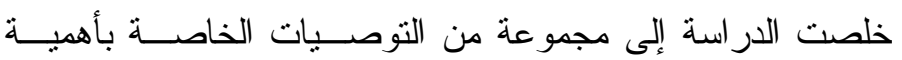

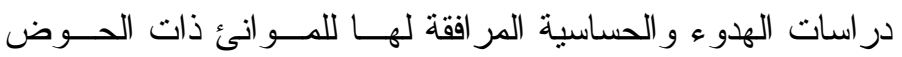



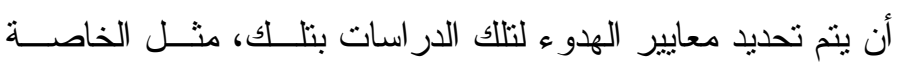

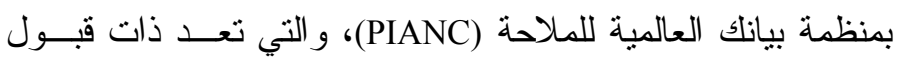
و اسع عالميا، مع فاعلية ومرونة عالية في التطبيق. 